\title{
SUARA SUNYI PEKERJA PABRIK PEREMPUAN
}

\author{
Nadiatus Salama, M.Si \\ Fakultas Dakwah IAIN Walisongo Semarang
}

\begin{abstract}
Abstrak
Peran pengembangan wawasan yang terkait dengan masalah pembangunan bangsa merupakan hal yang penting karena peran gender bisa meningkatkan keadilan dan persamaan hak. Meski demikian, ketidakadilan dalam dunia kerja masih kerap terjadi. Ketidakadilan sistem kerja telah menyebabkan pekerja perempuan menjadi miskin, bodoh, dan terasing. Selain itu, pekerja perempuan juga masih mendapat perlakuan yang melecehkan, memarjinalkan, dan mengsubordinasi. Perempuan perlu diberdayakan agar mereka bisa menggapai masa depan yang lebih baik.

Padahal, masih banyak pekerja perempuan yang belum mengetahui hak-haknya. cenderung pasif, dan pasrah pada keputusan perusahaan yang terkait dengan pengurangan pegawai dan pengurangan jam kerja. Ditambah lagi, mereka masih menyandang predikat sebagai mahluk domestik yang memiliki setumpuk pekerjaan rumah tangga. Mereka bekerja seperti mesin selama 24 jam tanpa sempat memikirkan pengembangan dirinya.

Kekhususan kondisi biologis perempuan juga turut berperan dalam meningkatkan labor turn over pada pekerja perempuan, sehingga pengusaha lebih memilih pekerja laki-laki karena mereka lebih menguntungkan bagi perusahaan, kecuali jika pekerja perempuan tersebut mau diberi upah rendah.

Sementara, sebagai pekerja dalam struktur pabrik, mereka bekerja pada unit paling bawah (unit produksi) yang tidak memiliki kuasa untuk memunculkan eksistensi dirinya. Hal-hal seperti ini bisa menyebabkan pekerja perempuan sangat tergantung kepada atasannya maupun sistem yang diterapkan di pabrik.
\end{abstract}

Kata Kunci: gender, perempuan, pekerja, pabrik 


\section{A. Gender dan Ketidakadilan}

Konsep gender terkait dengan masalah budaya yang merujuk pada klasifikasi sosial dari laki-laki dan perempuan menjadi maskulin dan feminin, yang diiringi dengan perbedaan waktu dan tempat. ${ }^{1}$ Jadi, gender tidak memiliki hubungan yang bersifat biologis (yang ditentukan oleh ciriciri genetika dan anatomis) serta bukan merupakan kodrat pemberian dari Tuhan. Perbedaan biologis merupakan perbedaan jenis kelamin yang bermuara dari kodrat Tuhan, sementara gender adalah perbedaan yang bukan kodrat dari Tuhan, tetapi diciptakan oleh kaum laki-laki dan perempuan melalui proses sosial dan budaya yang panjang. ${ }^{2}$

Laki-laki dan perempuan mempunyai peran yang berbeda-beda dalam masyarakat. Mereka memiliki pengalamannya sendiri dan keberadaannya yang juga berbeda satu sama lain. Perbedaan peran gender ini bisa disebabkan oleh berbagai faktor, mulai dari lingkungan alam, budaya, kebiasaan, cerita dan mitos, ${ }^{3}$ bahkan bisa pula berasal dari kebijakan pemerintah, keyakinan, penafsiran terhadap agama, tradisi atau kebiasaan maupun asumsi terhadap ilmu pengetahuan.

Jadi, jika mendiskusikan tentang masalah perempuan, maka aspek psikologis, biologis, dan sosiokultur merupakan hal yang saling berinterrelasi satu sama lain. Mental dan perilaku perempuan merupakan interplay (saling mempengaruhi) dari berbagai aspek ini, baik secara intrapsikis maupun interpsikis. Sehingga dapat dipahami jika perilaku perempuan tidak berdiri sendiri atau di luar konteks lingkungannya. Ia merupakan hasil dari keterpaduan dari berbagai aspek biopsikokulturalnya. ${ }^{4}$ h. 11 .

${ }^{1}$ Ann Oakley, Sex, Gender and Society, (England: Gower Publishing Company, 1985),

${ }^{2}$ Mansour Fakih, Membincang Feminisme: Diskursus Gender Perspektif Islam, (Surabaya: Risalah Gusti, 1996), h. 46.

${ }^{3}$ Julia Cleves Mosse, Gender dan Pembangunan, terj. Hartian Silawati, (Yogyakarta: Rifka Annisa dan Pustaka Pelajar, 1996), h. 5.

4 Nani Nurachman, "Wanita Indonesia: Identitas Sosial, Diri Pribadi, dan Pengembangannya dalam Organisasi Wanita. Suatu Studi Kasus tentang Kelompok Pimpinan Wanita", Disertasi, (Program Pascasarjana Universitas Indonesia, 1993). 
Terkait dengan masalah pembangunan bangsa, peran pengembangan wawasan yang terkait dengan masalah ini merupakan hal yang penting karena 'gender' bisa meningkatkan persamaan hak manusia dan keadilan. Pendekatan 'gender' dalam pembangunan membantu kepastian persamaan hak melalui tiga hal, yakni, pertama memberikan kepastian bahwa manfaat pembangunan akan sama bagi laki-laki dan perempuan; kedua, memberikan kepastian bahwa terdapat perbedaan permasalahan, dan terakhir, memberikan kepastian bahwa dampak negatif pembangunan tidak dialami secara tidak proporsional oleh laki-laki atau perempuan. ${ }^{5}$

Demikian pula dalam lingkungan kerja, terdapat bermacam-macam kerja yang dilakukan oleh laki-laki dan perempuan dalam masyarakat. Pembagian kerja tersebut berdasarkan gender (gender division of labour), misalnya, di dalam masyarakat primitif, menurut antropolog Ernestine Friedl, seperti yang dikutip oleh Arif Budiman, bahwa perempuan lebih penting dari laki-laki.

Ketika manusia primitif masih hidup mengembara dalam kelompok kecil, bahaya yang paling ditakuti adalah musnahnya kelompok yang disebabkan matinya anggota kelompok. Karena itu, jumlahnya harus diperbesar dengan memperbanyak lahirnya bayi-bayi, tetapi jumlah anak yang lahir masih terbatas. Untuk itu laki-laki banyak yang dikorbankan dengan pergi ke medan perang atau berburu, namun pekerjaan tersebut dapat membahayakan nyawa, maka muncullah pembagian kerja berdasarkan jenis kelamin. Perempuan bekerja di dalam rumah, laki-laki bekerja di luar. ${ }^{6}$ Sedangkan masyarakat Mbuti di Afrika dan masyarakat Bali memiliki peran gender yang tumpang tindih. Di kalangan orang kerdil, urusan berburu dan pengasuhan anak melibatkan laki-laki dan perempuan. Sementara di kalangan orang Ambara, sang ayah jarang menyentuh anak-anaknya selama dua tahun pertama, dan setelah dua tahun pertama, mengharapkan kepatuhan sepenuhnya dari anak-anaknya.

\footnotetext{
${ }^{5}$ Gillian Brown, Why Gender?, Smeru, No. 06 / Juni-Juli 1999, h. 3.

${ }^{6}$ Arif Budiman, Pembagian Kerja secara Seksual, Sebuah Pembahasan Sosiologis tentang Peran Wanita di dalam Masyarakat, (Jakarta: Gramedia, 1981), h. 30-31.
} 
Maka dapat dilihat bahwa, peran perempuan dan laki-laki adalah buatan atau ciptaan masyarakat. Maka dari itu, persepsi tentang gender dapat diubah, seperti masyarakat primitif yang berlaku demikian karena adanya keperluan untuk melestarikan kelompoknya. Perubahan tersebut, melalui proses sosialisasi tentang gender, yang berlangsung terus menerus, serta dilaksanakan di dalam keluarga dan masyarakat.

Selama ini, aplikasi dan implikasi gender belum sesuai dengan yang diharapkan karena faktor sosial dan budaya yang masih berperan kuat dalam mempengaruhi persepsi masyarakat. Perbedaan gender telah melahirkan ketidakadilan bagi laki-laki dan perempuan. Ketidakadilan ini bisa terwujud dalam berbagai bentuk, misalnya, subordinasi, marjinalisasi, dan beban kerja yang lebih banyak, serta stereotip.

Berbagai bentuk ketidakadilan ini kerapkali mengarah pada kekerasan. Safa'at mengidentifikasi lima bentuk kekerasan terhadap pekerja perempuan, yaitu marjinalisasi pekerja perempuan, bias gender dalam penggajian, kekerasan terhadap reproduksi pekerja perempuan, pelecehan maupun kekerasan seksual, serta bias gender dalam gerakan dan organisasi pekerja. $^{7}$

Sebenarnya, perbedaan gender tidaklah menjadi masalah yang besar selama tidak menimbulkan ketidakadilan bagi laki-laki maupun perempuan. ${ }^{8}$ Hanya saja, kadang ketidakadilan ini telah mengakibatkan pekerja perempuan menjadi miskin karena sistem pembagian kerja dan penggajian yang tidak adil.

\section{B. Suara Perempuan dan Ketidakadilan dalam Kerja}

Ketidakseimbangan relasi laki-laki dan perempuan yang terjadi selama lebih dari 3000 tahun, telah menjadikan perempuan tersubordinasi di berbagai lini secara kompleks dan heterogen. Tanpa disadari, negara

7 Safa'at, R., Pekerja Perempuan: Perlindungan Hukum dan Hak Asasi Manusia, (Malang: Penerbit IKIP Malang, 1998).

8 Trisakti Handayani dan Sugiarti, Konsep dan Teknik Penelitian Gender, (Malang: UMM Press, 2008), h. 14-15. 
juga turut melanggengkan dan memperkuat ketidakadilan gender ini. Bahkan, hal ini juga telah diadopsi oleh pelaku industri, akibatnya, pekerja perempuan -sebagai kelompok yang ditempatkan paling bawah dalam struktur industry- menjadi pihak yang paling dirugikan.

Para pekerja pabrik yang sebagian besar adalah perempuan yang status kerjanya sebagai pekerja tidak tetap, mereka merupakan kelompok yang sangat rentan menjadi korban PHK (pemutusan hubungan kerja). ${ }^{9}$ Di wilayah Jakarta, terdapat $88 \%$ perempuan yang menganggur. Prosentase ini bisa makin memburuk karena perempuan lebih sering diberhentikan dari tempat kerjanya dibandingkan pekerja laki-laki sebab mereka tidak dianggap sebagai kepala keluarga.

Pekerja perempuan merupakan kelompok yang paling menderita dari kebijakan ekonomi dan politik pemerintah. Banyak peraturan yang sering merugikan hak-hak perempuan di tempat kerja, terlebih pada kaum perempuan yang bekerja di industri manufaktur (garmen, tekstil, elektronik dan minuman) yang acapkali terkena PHK secara sepihak.

Industri manufaktur merupakan perusahaan padat karya yang menyerap banyak tenaga kerja perempuan serta tidak memerlukan persyaratan pendidikan dan keahlian yang tinggi. Data dari Badan Pusat Statistik pada tahun 2007 menyebutkan bahwa tingkat serapan tenaga kerja perempuan di industri manufaktur bisa mencapai 90\% dari 4,6 juta pekerja manufaktur, lebih tinggi ketimbang di sektor industri agribisnis dan pertambangan.

Data di atas menegaskan bahwa pada dasarnya lapangan kerja bagi perempuan masih terbatas karena hanya tersedia di sektor yang stereotip dengan label gender perempuan, yakni sektor industri yang diidentikkan dengan karakter dan peran perempuan, seperti menjahit (garmen), memintal (tekstil), kecantikan (kosmetik dan jamu), arloji (perlengkapan fesyen), dan yang berhubungan dengan jasa (termasuk pekerja domestik)

${ }^{9}$ Safa'at, R., Pekerja Perempuan .... 
dan periklanan yang menggunakan seksualitas perempuan sebagai daya penarik konsumen. Tampaknya, perempuan memang banyak terserap ke dunia kerja, tetapi sebenarnya lebih banyak terserap ke lapangan kerja manufaktur dan jasa. ${ }^{10}$

Meski dewasa ini, penggunaan tenaga kerja perempuan oleh pengusaha di bidang industri manufaktur menunjukkan peningkatan yang signifikan, namun muncul pula kecenderungan untuk melakukan desentralisasi produksi yang tersebar ke wilayah yang lebih kecil atau ke dalam industri-industri rumah tangga (yang dikerjakan dengan sistem borongan), yang para tenaga kerjanya relatif lebih patuh dalam bekerja dan mau menerima gaji yang rendah.

Kondisi pekerja perempuan yang miskin serta sempitnya lapangan pekerjaan telah memaksa pekerja perempuan untuk masuk ke sektor industri maupun jasa, termasuk pula melakukan kegiatan ekonomi pada sektor informal, seperti berdagang kecil-kecilan dan menjadi pembantu rumah tangga. Profesi yang demikian ini tetaplah sangat rentan dari sisi perlindungan dan tingkat penghasilan. Meski demikian, mereka tidak punya pilihan. Mereka akan tetap menjalaninya, meski sebenarnya ini merupakan pilihan terakhir karena menjadi pekerja pabrik bukanlah citacita awal mereka. Setelah memasuki dunia kerja, banyak pekerja perempuan yang mengalokasikan penghasilannya untuk membiayai kebutuhan keluarga di tempat asal, terutama untuk biaya makan, kesehatan, dan pendidikan anak-anaknya atau adik-adiknya atau bahkan orang tuanya. Hal ini mencerminkan kontribusi dan subsidi yang nyata dari pekerja perempuan terhadap kelangsungan hidup keluarganya dibandingkan dengan laki-laki. ${ }^{11}$

Masih banyaknya pekerja perempuan di pabrik yang rentan terhadap PHK massal disebabkan mereka tidak memiliki ikatan formal dengan perusahaan tempat bekerja karena alasan-alasan gender, seperti dianggap

\footnotetext{
${ }^{10} \mathrm{http}: / /$ frontoposisirakyatindonesia.blogspot.com/, diakses pada 3 Oktober 2011.

${ }_{11}$ Tjandraningsih, I., "Krisis dan Pekerja Pabrik: Dampak dan Masalah 'Jender"', Laporan, Lembaga Penelitian Smeru, 6, Juni-Juli 1999, h. 14-16.
} 
sebagai pencari nafkah tambahan, pekerja sambilan, dan juga alasan faktor reproduksinya, seperti menstruasi, hamil, melahirkan dan menyusui. Sebuah contoh kasus, yang terjadi di tempat kerja pembekuan ikan di Sulawesi Selatan. Dalam rangka merespon dampak krisis maka perusahaan telah merekrut pekerja-pekerja perempuan baru dengan status kontrak. Dengan sistem ini perusahaan hanya mempunyai kewajiban kepada pekerja ketika ada pekerjaan. Sistem ini menjadi sangat menguntungkan untuk industri yang mayoritas pekerjanya perempuan karena membebaskan perusahaan dari keharusan membayar berbagai kewajiban dan tanggung jawab, seperti cuti haid, cuti melahirkan, biaya kesehatan maupun libur tahunan.

Strategi lain yang bisa merugikan pekerja perempuan -yang biasa dilakukan oleh beberapa perusahaan dalam menghadapi krisis ekonomiadalah memindahkan sebagian proses pekerjaan keluar dari pabrik. Pekerja-pekerja perempuan yang telah berkeluarga diberi pilihan oleh perusahaan untuk membawa tugas pekerjaan ke rumah dan menyerahkan kembali hasil kerja yang telah diselesaikan dengan sistem borongan. Bagi sebagian pekerja perempuan, model kerja seperti ini dianggap menguntungkan karena dapat dilakukan sambil mengurus rumah tangga dan mengasuh anak di rumah. Untuk dapat menghasilkan upah yang lebih besar, mereka harus mencurahkan waktu dan tenaga yang lebih banyak. Mereka membuat waktu lembur sendiri. Strategi yang dilakukan perusahaan ini merupakan cara yang menguntungkan bagi perusahaan karena mengurangi biaya produksi, walaupun kadang perusahaan perlu menerapkan peraturan untuk menjaga kualitas produk. Strategi ini juga disukai perusahaan karena mengurangi munculnya tekanan solidaritas dan perlawanan pekerja, serta menghindari tuntutan massal dari karyawan. ${ }^{12}$

Hal lain yang merugikan pekerja perempuan adalah perusahaan cenderung merekrut pekerja perempuan yang masih muda belia untuk

${ }^{12} \mathrm{Ibid}$. 
mengganti pekerja perempuan yang sudah tua. Sebagai pekerjaan yang dikategorikan tidak membutuhkan tenaga terampil, jenis pekerjaan juga sangat spesifik, sederhana, dan repetitif, serta dapat dikuasai secara cepat tanpa membutuhkan pelatihan secara mendalam, maka upah yang diberikan juga tidak perlu tinggi dan perempuan (dengan mitos 'jari jemarinya yang halus') yang masih "hijau" ini merupakan tenaga yang sangat tepat untuk melakukannya. ${ }^{13}$

Ketidakadilan gender yang berlaku bagi pekerja perempuan dapat dilihat dari realita yang ada bahwa mereka banyak yang terlibat di industri padat kerja, khususnya industri tekstil dan garmen, yang diiringi dengan jam kerja yang panjang, membosankan, melelahkan, upah yang rendah, serta tempat kerja yang dipenuhi dengan polusi industri (udara yang dipenuhi dengan butiran air untuk menjaga kelembaban benang dan butiran serat kapuk).

Sementara, pekerja perempuan juga masih banyak yang belum mengetahui hak-haknya. Mereka tidak tahu bahwa mereka memiliki hak untuk berserikat, mengajukan ijin untuk cuti melahirkan, dan cuti haid dengan tetap memperoleh gaji penuh tanpa pemotongan. Pekerja perempuan juga menerima upah lebih rendah daripada rekan-rekan pria mereka, terutama dalam hal menerima tunjangan. Bahkan, di bidang hukum perburuhan, pekerja perempuan dianggap masih lajang sehingga tidak mendapatkan tunjangan keluarga, meski terkadang kenyataannya suaminya adalah seorang penganggur.

Meski beberapa penelitian menunjukkan bahwa dilakukannya PHK bisa bertujuan positif dan menguntungkan pihak perusahaan, seperti menghemat pengeluaran untuk membayar gaji pegawai, membuat struktur kontrol perusahaan menjadi lebih efektif, fleksibel, dan cepat dalam pengambilan keputusan karena rampingnya birokrasi serta memperpendek rantai komando. Di samping itu, survivors (pekerja yang terpilih

${ }^{13}$ Ibid. 
untuk tetap bekerja dalam perusahaan) juga akan bekerja lebih giat ${ }^{14}$ dan kinerjanya justru lebih baik. ${ }^{15}$

Namun demikian, PHK juga bisa merugikan perusahaan dan pekerja yang terlibat di dalamnya. ${ }^{16}$ Pihak eksekutif perusahaan sering meremehkan harga yang harus dibayar mahal setelah melakukan PHK, yang akhirnya justru mengakibatkan kegagalan dalam mencapai laba dan manfaat dari PHK. Hal ini bisa dilihat dari penelitian yang dilakukan oleh Wyatt Company Consultants, Amerika Serikat yang menunjukkan bahwa kurang dari 50\% perusahaan yang diteliti tidak mampu menurunkan biaya pengeluaran. Banyak perusahaan yang melakukan PHK gagal mencapai tujuannya, hanya terdapat $32 \%$ perusahaan yang mampu menaikkan laba, 25\% menaikkan produktivitasnya, 9\% memperbaiki kualitas produk, dan hanya 7\% yang mampu meningkatkan inovasi. ${ }^{17}$ Penelitian yang dilakukan oleh American Management Association pada tahun 1995 juga menyebutkan bahwa terdapat hanya kurang dari $37 \%$ perusahaan yang melakukan PHK yang bisa menaikkan produktivitas dan kurang dari separuhnya yang bisa meningkatkan keuntungan perusahaan. Meski ada perusahaan yang mampu meningkatkan upah pekerjanya hingga $16 \%$, namun kesenjangan antara penghasilan dan pengeluaran masih saja besar.

Sementara itu, dilihat dari perspektif pegawainya, khususnya bila dilihat berdasarkan gender, dibandingkan dengan pekerja laki-laki, pekerja perempuan yang terkena PHK -terutama perempuan yang berkeluargakecenderungan mengalami penurunan kesejahteraan jauh lebih nyata. Semua pengeluaran harus ditekan dan beberapa pengeluaran lain juga

\footnotetext{
${ }^{14}$ Brockner, J., Grover, S. L., \& Blonder, M. D., Predictor of Survivors' Job Involvement Following Layoffs: A Field Study. Journal of Applied Psychology, 73, 1988, h. 436.

${ }_{15}$ Bies, R., Mmaknan, C., \& Brockner, J., Just Laid Off, But Still a Good Citizen? Only If The Process Is Fair. Employee Rights and Responsibilities Journal, 6, 1993, h. 227.

${ }^{16}$ Cascio, W. F., Downsizing, What Do We Know? What Have We Learned? Academy of Management Executive, 11 (1), 1993, h. 95.

17 Hitt, M., Keats, B., Harback, H., \& Nixon, R., "Rightsizing: Building and Maintaining Strategic Leadership and Long-term Competitiveness", Organizational Dynamics, Vol. 23, No. 2, 1994, h. 18.
} 
harus dihilangkan. Prioritas pengeluaran tetap digunakan untuk makan. Berbagai strategi yang dilakukan diantaranya, seperti berhutang ke warung, menjual atau menggadaikan barang, menggunakan tabungan anak, mengandalkan sumbangan keluarga, mengandalkan penghasilan suami, mencoba berdagang kecil-kecilan atau menjadi pembantu rumah tangga. Strategi lain adalah mengerahkan anggota keluarga, khususnya anak-anak, untuk mencari penghasilan tambahan. Sementara, pekerja pria yang terkena PHK -terutama yang telah berkeluarga- segera mencari alternatif dengan berusaha di bidang informal, terutama di sektor jasa dan perdagangan.

Sementara itu, fakta lain menunjukkan bahwa pekerja perempuan cenderung lebih pasif dan lebih menerima keputusan perusahaan yang terkait dengan pengurangan pegawai dan pengurangan jam kerja. Kasus perlawanan pekerja umumnya dimotori oleh para pekerja pria.

Disadari atau tidak, pelaku industri telah turut serta dalam menciptakan sexual division of labor yang baru, yakni pekerjaan ringan pada industri padat kerja yang diberi upah murah, fasilitas yang tidak memadai, dan penuh dengan limbah serta berisiknya deru mesin. ${ }^{18}$ Ketika pulang ke rumah, mereka masih menyandang predikat sebagai mahluk domestik yang memiliki setumpuk pekerjaan rumah tangga. Kenyataan ini menunjukkan bahwa pekerja perempuan merupakan pekerja yang tangguh, teliti, sabar, dan tahan menderita. Mereka bekerja seperti mesin selama 24 jam tanpa sempat memikirkan untuk melakukan pengembangan diri guna meraih masa depan yang lebih baik.

Banyak penelitian yang menunjukkan bahwa kondisi pekerjaan dan ekonomi telah mempengaruhi hubungan pernikahan suami dan istri, pengasuhan terhadap anak, bahkan juga terhadap kesehatan mental dan fisik. Selain itu, fenomena ini juga bisa diperburuk lagi jika seseorang

${ }^{18}$ Widanti, A. Hukum Berkeadilan Jender, (Jakarta: Penerbit Buku Kompas, 2005), h. 9. 
mengalami jam kerja yang panjang, kerasnya kondisi kerja, serta rendahnya gaji yang diperoleh. ${ }^{19}$

Selain itu, pekerja perempuan juga masih mendapat perlakuan yang melecehkan, memarjinalkan, dan mengsubordinasi. Banyak pekerja perempuan yang diberi pekerjaan yang hanya merupakan sebuah langkah kecil dari seluruh proses produksi sehingga mereka merasa sedikit sekali perannya dalam pekerjaan, serta dengan jenis kerja yang juga mudah untuk dilakukan dan tidak perlu menggunakan pikiran yang rumit. Hal ini menyebabkan terjadinya proses pembodohan dan keterasingan yang terjadi pada pekerja perempuan. ${ }^{20}$

Kekhususan kondisi biologis perempuan (seperti saat haid, hamil, melahirkan, dan menyusui) juga turut berperan dalam meningkatkan labor turn over (tenaga kerja yang suka keluar masuk atau suka pindah kerja dari perusahaan ke perusahaan lainnya) pada pekerja perempuan, sehingga pengusaha lebih memilih pekerja laki-laki karena mereka lebih menguntungkan bagi perusahaan, kecuali jika pekerja perempuan tersebut mau diberi upah rendah. ${ }^{21}$

Berbagai identitas gender negatif yang terbentuk di tempat kerja kerap dipengaruhi oleh berbagai stereotip yang menempatkan laki-laki sebagai pencari nafkah yang terampil, kuat, dan memiliki kompetensi teknis. Sebaliknya, perempuan merupakan pekerja sekunder yang tidak terampil, lemah, dan memiliki keterbatasan kompetensi teknis. ${ }^{22}$

Pekerja perempuan di Jawa Tengah yang bekerja pada industri tekstil dan garmen sering mengalami dua budaya yang paradoksal, yaitu budaya publik yang universal, individual, serta penuh dengan dominasi kekuasaan dan kultur privat yang bersifat pelayanan, kewajiban, dan komitmen.

19 J.C. Chrisler, D.R. McCreary (eds.), Handbook of Gender Research in Psychology, (London: Springer Science, Business Media, 2010), h. 401.

${ }^{20}$ Widanti, A. Hukum Berkeadilan Jender, h. 98-99.

${ }^{21}$ Ibid., h.10.

22 J. Humprey, Gender, Pay, and Skill: Manual Workers in Brazilian Industry, dalam H. Afsahar (ed) (London: Tavistock, 1985), h. 214-218. 
Sementara, sebagai pekerja dalam struktur pabrik, mereka bekerja pada unit paling bawah (unit produksi) yang tidak memiliki kuasa untuk memunculkan eksistensi dirinya. Hal-hal seperti ini bisa menyebabkan pekerja perempuan sangat tergantung kepada atasannya maupun sistem yang diterapkan di pabrik. ${ }^{23}$

Di Indonesia, ketidakadilan gender ini terus berusaha diruntuhkan oleh para penggiat kesetaraan gender agar, meskipun perempuan itu berbeda dengan laki-laki, perempuan tetap memiliki hak untuk diperlakukan setara sebagai sesama manusia. Perempuan perlu diberdayakan agar mereka bisa menggapai masa depan yang lebih baik.[]

\section{Daftar Pustaka}

Amundson, N. E., Borgen, W. A., Jordan, S., \& Erlebach, A. C., "Survivors of Downsizing: Helpful and Hindering Experiences", The Career Development Quarterly, March, Vol. 52, No. 3, 2004, pp. 256-272.

Bies, R., Mmaknan, C., \& Brockner, J., "Just Laid Off, But Still a Good Citizen? Only if The Process is Fair", Employee Rights and Responsibilities Joumal, Vol. 6, 1993, 227-238.

Brockner, J., Greenberg, J., Brockner, A., Bortz, J., Davey, J. \& Carter, C., Layoffs, "Equity Theory and Work Performance: Further Evidence of The Impact of Survivors Guilt", Academy of Management Joumal, Vol. 29, No. 2, 1986, pp. 374-384.

Brockner, J., Grover, S. L., \& Blonder, M. D., "Predictor of Survivors' Job Involvement Following Layoffs: A Field Study", Joumal of Applied Psychology, Vol. 73,1988, pp. 436-442.

Brown, G. "Why Gender?" Bulletin Smeru, No. 06, Vol. 3, 1999.

Browne, J., The Future of Gender, Cambridge, UK: Cambridge University Press, 2007.

${ }^{23}$ Widanti, A. Hukum Berkeadilan Jender, h. 21. 
Budiman, A., Pembagian Kerja secara Seksual, Sebuah Pembahasan Sosiologis tentang Peran Wanita di dalam Masyarakat, Jakarta: Gramedia, 1981.

Cameron, K.S., "Strategies for Succesful Organizational Downsizing", Human Resource Management, Vol. 33, No. 2, 1994, pp. 189-211.

Cascio, W. F., Downsizing, "What Do We Know? What Have We Learned?" Academy of Management Executive, Vol.11 No. 1, 1993, pp. 95-104.

Cascio, W. F. (ed.)., Human Resources Planning, Employment, and Placement. Washington, DC: Bureau of National Affairs, 1998.

Chrisler, J. C. \& McCreary, D. R. (eds.)., Handbook of Gender Research in PsychologyVol. 2: Gender Research in Social and Applied Psychology, New York: Springer, 2010.

Eagly, A. H. Beall, A. E. \& Sternberg, R.J.(eds.)., The Psychology of Gender. 2nd ed. Spring Street, NY: The Guilford Press, 2004.

Fakih, M., Membincang Feminisme: Diskursus Gender Perspektif Islam, Surabaya: Risalah Gusti, 1996.

Handayani, T. dan Sugiarti, Konsep dan Teknik Penelitian Gender, Malang: UMM Press, 2008.

Hitt, M., Keats, B., Harback, H., \& Nixon, R., "Rightsizing: Building and Maintaining Strategic Leadership and Long-term Competitiveness", Organizational Dynamiss, Vol. 23, No. 2, 1994, pp.18-32.

http://frontoposisirakyatindonesia.blogspot.com/, diakses pada 3 Oktober 2011.

Humprey, J., Gender, Pay, and Skill: Manual Workers in Brazilian Industry, dalam H. Afssahar (ed). London: Tavistock, 1985.

Mishra, A. K. \& Spreitzer, G. M., Explaining How Survivors Respond to Downsizing: The Role of Trust, Empowerment, Justice, and Work Redesign. Academy of Management Review, Vol. 23 No. 3, 1998, pp. 567-589.

Mosse, J. C., Gender dan Pembangunan, terj. Hartian Silawati, Yogyakarta: Rifka Annisa dan Pustaka Pelajar, 1996.

Nurachman, N., "Wanita Indonesia: Identitas Sosial, Diri Pribadi, dan Pengembangannya dalam Organisasi Wanita. Suatu Studi Kasus tentang Kelompok Pimpinan Wanita", Disentasi: Program Pascasarjana Universitas Indonesia, 1993. 
Oakley, A.,Sex, Gender and Society, England: Gower Publishing Company, 1985.

Safa'at, R., Pekerja Perempuan: Perlindungan Hukum dan Hak Asasi Manusia, Malang: Penerbit IKIP Malang, 1998.

Tjandraningsih, I., Krisis dan Pekerja Pabrik: Dampak dan Masalah 'Gender'. Lembaga Penelitian Smeru, 6, Juni-Juli, 1999, p. 14-16.

Widanti, A., Hukum Berkeadilan Gender, Jakarta: Kompas, 2005. 